\title{
REGISTROS NOTICIOSOS SOBRE A ESCOLA PROFISSIONAL DE ENFERMEIROS E ENFERMEIRAS NA REVISTA "O BRAZIL-MEDICO",1890-1922
}

\author{
REGISTERED NEWS ABOUT THE PROFESSIONAL SCHOOL OF NURSES \\ WITHIN THE JOURNAL "O BRAZIL-MEDICO" - 1890-1922
}

\author{
REGISTROS NOTICIEROS SOBRE LA ESCUELA PROFESIONAL DE \\ ENFERMEROS Y ENFERMERAS EN LA REVISTA "O BRAZIL-MEDICO", 1890-1922
}

\author{
Almerinda Moreira* \\ Fernando Porto** \\ Taka Oguisso***
}

Moreira A, Porto F, Oguisso T. Registros noticiosos sobre a escola profissional de enfermeiros e enfermeiras na revista "O Brazil-Médico", 1890-1922. Rev Esc Enferm USP 2002; 36(4): 402-7.

\section{RE SUMO}

Estudo histórico descritivo com o objetivo de identificar registros noticiosos sobre a Escola de Enfermagem Alfredo Pinto, antiga Escola Profissional de Enfermeiros e Enfermeiras (EPEE), veiculadas na revista mencionada no periodo referido. A metodologia utilizada foi a análise documental como técnica de pesquisa. A revista foi publicada de forma ininterrupta durante esse periodo de 32 anos e 1.632 exemplares foram consultados. Foram encontradas 16 noticias alusivas à EPEE, ao Hospital Nacional de Alienados, à Enfermagem e Cursos de Enfermagem. Desse total, apenas cinco noticias referiamse diretamente à EPEE. Analisando seu conteúdo despontam duas idéias fundamentais: 1) a EPEE teve duas inaugurações, em 1897 e 1906, o que ratifica o Decreto de criação em 27/09/1890; e, 2) a dificuldade de operacionalização da EPEE, àquela época, em virtude da baixa qualificação dos candidatos a alunos.

PALAVRAS-CHAVE: Enfermagem. História da enfermagem. Escolas de enfermagem.

\begin{abstract}
Historical and descriptive study with the objective to identify registered news about the Professional School of Nurses (PSN), currently Alfredo Pinto School of Nursing, in the mentioned journal and referred period. Methodology utilized was the documental analysis. The journal was regularly published and 1632 issues were examined, from that period of 32 years. It was found 16 news related to the PSN, the National Mental Hospital, Nursing and Nursing courses. From this total, only five news were indeed directely related to PSN. Analysing their content, two fundamental ideas appear: 1) the PSN had two openings, in 1897 and in 1906, which ratifies its legal creation on 27/09/1890 and 2) it indicates the operational difficulties of PSN, at that time, due to the low qualification of the candidates to the nursing school.
\end{abstract}

KEYWORDS: Nursing. Nursing history. Schools, nursing.

\section{RESUMEN}

Estudio histórico descriptivo con el objetivo de identificar los registros noticieros referentes a la actual Escuela de Enfermeria Alfredo Pinto, antigua Escuela Profesional de Enfermeros y Enfermeras (EPEE) en la revista mencionada y en el periodo referido. La metodologia utilizada fue un análisis documental como técnica de investigación. La revista fué publicada sin interrupción durante todo ese periodo de 32 anos y 1632 ejemplares fueron consultados. Fueron encontradas 16 noticias alusivas a EPEE, al Hospital Nacional de Alienados, a la enfermeria y cursos de enfermería. De ese total solamente cinco noticias, se referian a asuntos relacionados directamente a EPEE. Analisandose su contenido, dos ideas fundamentales surgen: 1) de que la EPEE tuvo dos inauguraciones, en 1897y 1906, lo que ratifica el Decreto de creación de 27/09/1890 y 2) la dificultad de operacionalización de la EPEE, en la época, debido a la baja calificación de los candidatos a alumnos.

PALABRAS -CLAVE: Enfermería. História de la enfermería. Escuelas de enfermería.

\footnotetext{
* Professora Adjunta da Escola de Enfermagem Alfredo Pinto da Universidade do Rio de Janeiro, UNIRIO, Doutoranda da EEUSP

** Professor Assistente da Escola de Enfermagem Alfredo Pinto da Universidade do Rio de Janeiro, UNIRIO, Mestre em Enfermagem

***Professora Titular do Departamento de Orientação Profissional, da Escola de Enfermagem da Universidade de São Paulo.
} 


\section{INTRODUÇÃO}

A Escola Profissional de Enfermeiros e Enfermeiras (EPEE), hoje Escola de Enfermagem Alfredo Pinto, da Universidade do Rio de Janeiro (UNIRIO), teve sua criação pelo Decreto no. 791 , de 27 de setembro de 1890, assinado pelo Marechal Deodoro da Fonseca, primeiro Presidente da República, na tentativa de resolver um problema urgente da assistência aos alienado(1). Com isso as atividades de Enfermagem, que ainda tinham cunho de cuidado caritativo e assistencial religioso, passariam a ser parte do exercício de uma profissão e teve início a profissionalização dessa atividade, a partir do ensino oficial.

Moreira $^{(2)}$ relata as dificuldades para desvelar fatos do período compreendido entre 1890 a 1920, o que nos motivou ao empenho pela busca de notícias veiculadas na imprensa àquela época.

Nessa busca de notícias, foi encontrada uma revista, cuja publicação foi iniciada em 1887, com o nome de "O Brazil-Médico". Não existindo ainda publicação específica alguma vinculada à área de saúde, no Brasil, certamente este era o único periódico especializado à época.

Constitui objetivo deste trabalho identificar as notícias referentes à EPEE publicadas na revista "O Brazil-Médico", inicialmente apenas no período de 1890 a 1920, posteriormente estendido até 1922, uma vez que nada havia sido encontrado de 1907 a 1920. Os fatos noticiosos registrados nesse periódico irão, pois, compor o objeto deste estudo.

Trata-se, portanto, de um estudo histórico descritivo, no qual será utilizada a análise documental como técnica de pesquisa. Ludke, André(3) ensinam que os documentos:

-constituem uma fonte estável e rica;

- podem ser consultados várias vezes e servir de base a diferentes estudos, o que dá mais estabilidade aos resultados obtidos;

- constituem uma fonte poderosa de onde podem ser retiradas evidências que fundamentem afirmações e declarações do pesquisador;

- não são apenas uma fonte de informações contextualizada, mas surgem num determinado contexto e fornecem informações sobre esse mesmo contexto.

A relevância deste estudo está na sua contribuição para a construção da História da Escola de Enfermagem Alfredo Pinto, antiga EPEE, na medida em que desvela o seu contexto histórico na Enfermagem Brasileira.

\section{A revista "O Brazil-Médico"}

A revista "O Brazil-Médico"* era um órgão semanal de divulgação de interesse científico, político, prático e profissional da classe médica brasileira, fundada em 1887 e editada até 1956, na cidade do Rio de Janeiro. Era impressa na Rua do Rosário ${ }^{\circ} 140-$ $\mathrm{RJ}$, sob a direção e redação principal do Dr. A. A. Azevedo Sodré, ex-Diretor da Faculdade de Medicina do Rio de Janeiro, e tinha como Redator-Gerente, Dr. Bulhões de Carvalho.

A publicação era semanal, dividida em várias seções, com tamanho 300 × $200 \mathrm{~mm}$. A capa era de um papel diferenciado em relação às páginas do conteúdo, que, devido ao tempo e manuseio, seria muito dificil identificar a origem do papel.

Vale destacar que, no conteúdo dessa revista, além do exposto acima, como produção científica da classe médica e uma coluna intitulada "Chronica e Notícias", foram encontrados anúncios ou propagandas de boticas, serviços de balneoterapia, medicamentos, dentre outras, demonstrando ser um periódico que tentava oferecer um panorama da medicina e da saúde pública, à época.

Na coluna "Chronica e Notícias" houve algu-mas referências à EPEE, assim como notícias sobre o Hospital Nacional de Alienados (HNA), onde a escola estava inserida. O HNA estava situado à avenida Pasteur, prédio hoje ocupado, parcialmente, pela Universidade Federal do Rio de Janeiro - UFRJ e pela UNIRIO.

\section{A busca de noticias sobre a EPEE na Revista "O Brazil-Médico"}

$\mathrm{Na}$ busca de notícias referentes .à EPEE, pesquisas foram feitas na Biblioteca da Faculdade de Medicina da Universidade de São Paulo - USP, e na Biblioteca da Academia Nacional de Medicina, no Rio de Janeiro, detendo-nos no período de 1890 até 1922.

A pesquisa foi realizada nos meses de setembro a novembro de 2000 , em cujo período foram consultados 1.632 exemplares da revista O BrazilMédico, que foi publicada de forma ininterrupta, durante todo o período citado.

Dos milhares de exemplares consultados, foram selecionadas 16 notícias alusivas à EPEE, ao HNA, à Enfermagem e Cursos de Enfermagem. Dessas notícias, através de um critério de seleção que contemplasse o objeto do estudo, foram selecionadas cinco notícias referentes ao período de 1890 a 1922.

O critério de seleção utilizado foi a percepção de que a notícia informasse sobre assuntos relacionados diretamente à EPEE, para tentar contemplar o objetivo do estudo, como registro noticioso histórico da época.

\footnotetext{
* Esclarecemos ,que o nome da Revista e o título das seções estão escritos com a ortografia da época.
} 
Das cinco notícias selecionadas, houve três na seção de "Chronica e Notícias", dos anos de 1890 e 1897, duas na seção Boletim Semanal, dos anos de 1897 e 1906, uma na seção Comunicação, do ano de 1922, e a última em Notas e Informações, no ano de 1922.

Essas notícias eram apresentadas na revista como texto, dividido em duas colunas verticais de doze a cento e catorze linhas, aproximadamente.

Para se ter uma idéia de como a notícia era divulgada, cada uma delas foi listada, em ordem cronológica, com a data da publicação, a seção na qual estava inserida, o título da notícia e o respectivo conteúdo, resumido, uma vez que o texto na íntegra, seja do Decreto de criação da EPEE, com seus requisitos de ingresso e programas, seja do discurso proferido, seja da fuga de pacientes internados no HNA, não era inteiramente dedicado à questão da Enfermagem, em si. Optou-se pelo resumo da notícia e não sua apresentação na íntegra, para ater-se aos limites do objetivo proposto e, ao mesmo tempo, estimular e manter o interesse pela História da Enfermagem, como campo de pesquisa e objeto de estudo, além da utilização racional do espaço.

\section{Noticias sobre a EPEE}

Primeira notícia - datada de 8 de outubro de 1890, na seção Chronica e Notícias, página 300, com o título "Hospital Nacional de Alienados". Conteúdo: A notícia destaca como uma idéia grandiosa a criação da EPEE pelo diretor do HNA, Dr. Teixeira Brandão, em 27 de setembro de 1890, com o fim de preparar enfermeiros e enfermeiras para os hospícios e hospitais da República. Refere ainda que poderá ser ampliado o horizonte da atividade feminina, proporcionando à mulher um meio honesto e altamente humanitário de conseguir os meios de subsistência e que preparará indivíduos que serão verdadeiros auxiliares dos médicos. A seguir, transcreve na integra o Decreto que cria a EPEE.

Segunda noticia - datada de $1^{9}$. de abril de 1897 , na seção Chronica e Notícias, página 109, com o título "Escola de Enfermeiros". Conteúdo: A notícia destaca a inauguração da EPEE no HNA, no dia 3 de abril de 1897, sob a direção do Dr. Márcio Nery (médico-chefe do Hospício). Enfatiza a importância da Escola para a população e a classe médica. Salienta que as aulas de anatomia descritiva, fisiologia e noções de propedêutica já haviam iniciado.

Terceira notícia - datada de $1^{\circ}$ de abril de 1897 , na seção Boletim Semanal, página. 208, com o título "O Hospício Nacional e a Escola de Enfermeiros". Conteúdo: Discurso assinado por Dr. C. S. que protesta sobre as notícias veiculadas na imprensa, à época, quando dois internos criminosos fugiram do HNA e tenta esclarecer alguns conceitos na área psiquiátricatais como: alienação mental, loucura e outros. Registra, com pesar, a saída das Irmãs de Caridade e sobre as conseqüências de tal fato. Referese ainda à criação da EPEE, para alunos de ambos os sexos. Enfatiza a importância do profissional de enfermagem em detrimento daquelas congregacionais. Finaliza dizendo ser da maior importância a efetivação da Escola de Enfermeiros com formação generalista para o serviço público.

Quarta notícia - datada de $1^{\circ}$. de abril de 1906, na seção Boletim da Semana, página 133 e 134, com o título "A Escola de Enfermeiros". Conteúdo: Discurso político assinado por F.F. em que divide sua idéia em dois momentos: no primeiro momento refere-se à desqualificação e ao despreparo dos técnicos e dos "pseudo-enfermeiros" atuantes nos hospitais filantrópico e militar. No segundo momento exalta a iniciativa do HNA em manter um curso de Enfermeiros de maior padrão que os de Paris, à época, utilizandose do corpo médico para o preparo dos enfermeiros. Aponta ainda para a excelência que a assistência pública se tornaria se adotasse o exemplo dessa instituição.

Quinta notícia - datada de 25 de março de 1922, na seção Comunicação, página 145 e 146, com o título "Pequena Cirurgia". Conteúdo: Discurso do Dr. Oscar Ramos, chefe do Serviço Cirúrgico, na aula inaugural da disciplina, à época denominada, cadeira de Pequena Cirurgia, Curativos e Aparelhos, na EPEE. A notícia apresenta um panorama do conteúdo da disciplina onde descreve o tratamento pré e pósoperatório para clientes acometidos de ferida cirúrgica, problemas ortopédicos e os cuidados para com as parturientes e o recém nato em sala de parto. Destaca as modernas aquisições aprendidas coma guerra, bem como enfatiza a importância e as qualidades necessárias para ser um bom enfermeiro, ou seja auxiliar do médico.

\section{Comentários sobre os registros noticiosos}

Como pode ser observado nos textos selecionados, a notícia sobre a criação da EPEE na revista "O BrazilMédico", com a finalidade de preparar enfermeiros e enfermeiras para os Hospícios e Hospitais da República, é considerada uma idéia grandiosa. Esta notícia ratifica a importância do Decreto $n^{\circ} 791 / 1890^{(1)}$, com o argumento de suprir a falta de mão de obra no HNA em decorrência da saída das Irmãs de Caridade e resolve o problema das pessoas do sexo feminino, com dificuldade de profissionalização.

Vale destacar que apesar do argumento de se resolver o problema de pessoas do sexo feminino, a EPEE também se destinava ao preparo de profissionais do sexo masculino(2).

Esse Decreto é publicado na íntegra dentro dessa seção, exaltando a iniciativa, na época, mas que, 
na verdade, registrou um marco factual da História da Enfermagem no Brasil, tendo em vista que, até aquele momento, não existia, no país, ensino oficial de Enfermagem.

Kirschbaum(4) corrobora com essa afirmativa ao citar que, o Decreto 791/1890 constituiu-se na primeira iniciativa de ensino oficial de Enfermagem no país, ao que pode ser acrescentado que, não só do ensino oficial da Enfermagem, mas, também do início, de uma nova profissão no Brasil.

O ensino de Enfermagem não oficial, antes do período acima descrito, era decorrente da prática de "enfermagem" realizada pelas religiosas, tendo como objetivo o cuidar da alma e do corpo como forma de caridade(5).

O objetivo das religiosas era seguir os preceitos dos Jesuítas no período Colonial, institucionalizandoas nas Santas Casas de Misericórdia, onde as religiosas praticavam sua assistência, matizada pelas cores da religião.

Itayra(6) relata que as Irmãs de Caridade não eram denominadas Enfermeiras, apesar de, em sua percepção, apontar para o oposto, pois exerciam todo trabalho considerado atualmente como de enfermagem, e mais precisamente da Enfermeira, sendo exercentes de enfermagem os enfermeiros, escravos, ex-escravos e africanos livres, dentre outros, sob a coordenação das Irmãs de Caridade.

Esta assistência aos doentes não era considerada uma prática profissional adequada à Enfermagem, pois a realização do cuidado baseava-se em um saber empírico transmitido de geração a geração, através da tradição oral, não caracterizando a Enfermagem como profissão(4).

Com a idéia de criação da EPEE, no HNA, a forma de assistência de natureza caritativa e assistencial das religiosas passa a ser rejeitada no meio médico.

O Decreto no. 142, de 11 de janeiro de 1890(7), determina a desanexação do hospício e suas colônias da Santa Casa de Misericórdia e, muda até de nome, de Hospício Pedro II para Hospital Nacional de Alienados. $\mathrm{Na}$ seqüência do fato, em 15/02/1890, é criada a Assistência Médico-Legal aos Alienados, e aprovado seu regulamento em 21/06/1890, e designado novo Diretor para o Hospital. Este fez várias modificações, que culminaram com a saída repentina das Irmãs de Caridade, que se sentiram diminuídas no tipo de cuidados que deveriam prestar dali por diante. Enquanto nas Santas Casas de Misericórdia, essa saída ocorreu de forma gradativa, no Hospício foi abrupta, e desencadeou uma crise enorme de pessoal para cuidar dos alienados ${ }^{(2)}$.

Na lógica dos fatos antes expostos, a situação requeria soluções rápidas para a crise, tais como a criação de uma escola para preparar os futuros enfermeiros e a vinda de sete enfermeiras francesas com o objetivo de organizar o serviço de enfermagem nos estabelecimentos da Assistência Médico-Legal aos Alienados.

Essas enfermeiras francesas, não religiosas, contratadas pelo governo brasileiro, pelo periodo de dois anos (1891-1893), acabaram permanecendo no HNA por mais quatro anos, segundo Kirschbaum(4), que afirma ainda que, a permanência delas antecedeu em trinta anos a vinda das enfermeiras norteamericanas para o Departamento Nacional de Saúde Pública, com o objetivo de inserir a Enfermagem Moderna no Brasil. O fato de importar saberes e práticas da Europa pode ser considerado como o segundo marco da História da Enfermagem.

A notícia de 1897 refere-se à inauguração da Escola de Enfermeiros, o que deixa uma lacuna histórica sobre a EPEE a partir de 1890, pois não foi encontrado relato sobre a inauguração dessa escola no ano de sua criação. Por outro lado, segundo dados existentes, 1897 coincide com o ano em que as enfermeiras francesas saem do HNA. Em documentos consultados, há registros de falecimento de duas dessas enfermeiras, mas não se tem maiores registros do destino das outras cinco enfermeiras ${ }^{(2)}$.

A terceira notícia, com a mesma data da segunda, mas em outra seção da revista, intitulada "Hospício Nacional e Escola de Enfermeiros", registra um discurso lamentando a saída das Irmãs de Caridade e suas conseqüências e sobre a criação da EPEE para alunos de ambos os sexos. Enfatiza a importância da efetivação da Escola para formação de enfermeiros generalistas e não só daqueles voltados para a psiquiatria, e ainda, de que o governo deveria providenciar a execução do artigo 26 do Decreto $n^{\circ} 896^{*}$, de 29/06/1892'8', independentemente do Diretor da instituição, como, por exemplo, para captar discentes para a Escola.

A EPEE, conforme notícia de 1897, é "inaugurada", porém funciona com dificuldades, conforme consta em Relatório do HNA, datado de 1899'9', cumprindo o prazo de dois anos para se formar enfermeiros, de acordo com o Decreto de criação da Escola.

Esse relatório, apresentado pelo Diretor do HNA, destinava-se ao Ministro da Justiça e Negócios Interiores, e relata a dificuldade que encontrou para o funcionamento da Escola pela absoluta falta de candidatas nas condições regulamentares. Em outras palavras, as alunas, no total de três, eram órfãs oriundas das Pretorias do Rio de Janeiro, vinham sem educação formal, analfabetas, com pouco amor ao trabalho e má vontade para com os doentes. Tal fato resultou no retorno dessas órfãs ao Pretor, da 144 Pretoria em 05/03/1899, e a Escola ficou sem alunas. Em 1900 e 1901, outro fato, mencionado nos respectivos Relatórios do HNA, salienta que a Escola

\footnotetext{
* Decreto 896 de, 29/06/1892; regulamenta a Assistência Médico-Legal aos Alienados.
} 
permanecia com dificuldades de operacionalização, porque as candidatas encaminhadas para freqüentar a escola, não preenchiam as condições regulamentares ${ }^{(10-11)}$. Cabe destacar que o Decreto 791 / ao criar a EPEE, exigia do candidato para admissão "saber ler e escrever corretamente e conhecer aritmética elementar"(1).

Segundo documentos consultados por Moreira (2), a justificativa oferecida ao governo para a criação da Escola menciona as órfãs como possiveis alunas da EPEE, mas os Relatórios do HNA comprovam a impossibilidade de se formar enfermeiras com as órfãs oriundas das Pretorias.

No período de 1897 a 1905 não foram encontradas outras notícias referentes à EPEE; contudo, é sabido que em 1905 a Escola teve outra inauguração(2).

A quarta noticia, de 1906, na seção "Boletim da Semana", com a manchete "A Escola de Enfermeiros", apresenta num discurso político, assinado por F.F, uma exaltação à Escola por possuir um modelo de ensino de "maior padrão que os de Paris" e critica os "pseudo-enfermeiros" atuantes nos hospitais filantrópicos e militares.

Com essa notícia de 1906 pode-se vislumbrar que os alunos, oriundos da EPEE, já eram ponto de referência para as outras instituições de saúde nas quais ainda se praticava a enfermagem sem qualquer preparo de seu pessoal. Foram também mencionados: a profundidade do conteúdo das disciplinas ministradas no curso, e o vasto campo de atuação para o qual eram preparados os enfermeiros, demonstrando que Escola não preparava profissionais de enfermagem apenas para o hospício, como muitos poderiam pensar.

Essa forma de pensar de que a EPEE formaria profissionais de enfermagem somente para a psiquiatria é apontada por Kirschbaum(4), ao argumentar que era uma opção, do modelo francês, adotada pelos psiquiatras brasileiros em detrimento do modelo Nigthingaleano, já difundido na Europa e EUA, que dava à "matron" a direção do pessoal de enfermagem e a administração do ambiente físico. Os psiquiatras brasileiros necessitavam se impor no processo de reorganização do hospício, utilizando o modelo francês que previa a centralização do espaço e dos agentes de enfermagem pelos médicos.

A quinta e última notícia encontrada no período de 32 anos, de 1890 a 1922, na revista "O Brazil Medico", refere-se a um discurso do Dr. Oscar Ramos sobre sua aula inaugural para os alunos da EPEE, ocorrida no ano letivo de 1922, na disciplina de Pequena Cirurgia, Curativos e Aparelhos. Discorre sobre o conteúdo da disciplina e as modernas aquisições científicas aprendidas com a guerra. A publicação, na íntegra, do discurso do Dr. Oscar registra os avanços dos cuidados de enfermagem com o pós-guerra, ressaltando, além do conhecimento técnico, as qualidades necessárias para ser um bom enfermeiro, ou seja, ser auxiliar do médico.

A guerra, mencionada no corpo da notícia, referese à $1^{a}$ Guerra Mundial, de 1914 a 1918, cujo período segundo Ballariny ${ }^{(12)}$, foi aliado ao progresso das ciências médicas do fim do século XIX, dando um surpreendente incremento ao hospital do século XX. Como se pode observar o fator guerra foi de transcendental importância para a assistência médico-social do Século XX.

Apesar de ser um período de intensa fermentação social, inclusive com constantes rebeliões militares, a EPEE, por sofrer influência direta da psiquiatria, beneficiou-se da autonomia que esta área recebeu, à época, como especialidade médica, pois em 1920, tinha ocorrido um aumento importante no número de estabelecimentos destinados aos doentes mentais ${ }^{(2)}$.

Apenas para fazer um paralelo entre a trajetória do início do ensino de enfermagem no Brasil e como ocorreu em Portugal, com base nos escritos de Soares(13), observa-se semelhança cronológica, pois, lá também a primeira escola de enfermagem foi criada na mesma época, isto é, em 1881. Refere Soares ${ }^{(13)}$ que foi "uma iniciativa voluntarista do administrador dos Hospitais da Universidade de Coimbra, Costa Simões, a expensas suas e sem reconhecimento oficial". Explica que esse administrador tinha conhecimento de escolas de enfermagem, que funcionavam em Paris, desde 1878, com o fim de preparar pessoal laico que substituísse as religiosas nos serviços hospitalares. Mas, em Portugal, não era para substituir irmãs de caridade que ele pretendia criar uma escola, pois nunca congregações religiosas tinham tido tal encargo nos hospitais de Coimbra. Embora a inauguração tenha sido registrada pela imprensa local, a escola não progrediu porque esse administrador mudou-se de Coimbra e o professor, seu principal colaborador, adoeceu gravemente.

Também em Coimbra, como no Brasil, as exigências para aqueles que pretendiam exercer enfermagem nos hospitais eram que soubessem ler, escrever e fazer operações de aritmética, comprovado por exame escrito.

Em 1886, Tomás de Carvalho, um médico com o título de enfermeiro-mor*, do Hospital Real de São José e Anexos, propôs ao Ministério dos Negócios do Reino, em Lisboa, a criação de um curso de enfermeiros naquele Hospital, o que é concretizado com a publicação de uma portaria no dia 26 de janeiro de 1886 autorizando o dispêndio de uma soma para o ensino prático de enfermeiros, o que veio a ocorrer em janeiro de 1887, mas com duração efêmera pois funcionou somente até 1889 , quando o curso foi extinto.

\footnotetext{
* Cabe destacar que o cargo de enfermeiro-mor, criado em 1564, era ocupado por aquele que exercia a função de administrador do hospital, nomeado pelo Rei. Era geralmente ocupado por médico.(13)
} 
Finalmente, em 1901, outro enfermeiro-mor, Curry Cabral, propôs a criação da Escola Profissional de Enfermeiros, efetivada pela publicação de um Decreto em Diário Oficial de 10 de setembro de 1901. A Escola começou a funcionar em 26 de outubro de 1901 no Hospital Real de São José. Em 1918 ocorre uma reforma nos hospitais que passaram a ser denominados Hospitais Civis de Lisboa e a escola recebeu o nome de Escola Profissional de Enfermagem.

\section{CONSIDERAÇÕES FINAIS}

O presente estudo, ao identificar as notícias referentes à EPEE na revista "O Brazil-Médico", apontou para duas idéias fundamentais:

1) de que a EPEE teve duas inaugurações, em 1897 e 1906, o que vem a ratificar o Decreto de criação em 27/09/1890 e;

2) a dificuldade de operacionalização da EPEE em virtude da baixa qualificação dos candidatos a alunos.

Essas idéias constituem uma importante contribuição para a construção da história da atual Escola de Enfermagem Alfredo Pinto, pois há vários anos que se busca completar as lacunas existentes em sua trajetória histórica. Estudos como os de Gussi (14), Moreira ${ }^{(2)}$, Kirschbaum(4), dentre outros, já vinham preenchendo algumas dessas lacunas, mas o espaço temporal do nasce-douro até os dias de hoje é extenso e ainda incompleto. $\mathrm{E}$ possivel que existam diversos marcos factuais, que fizeram parte dessa história e que se perderam ao longo do tempo, como por exemplo, um dado novo, agora encontrado da inauguração da EPEE em 1897.

Embora este estudo não responda a todos os questionamentos, aponta um caminho possivel para um futuro preenchimento, devido aos dados encontrados que, analisados em conjunto com outras informações, irão possibilitar e estimular a pesquisa em outras fontes. Informações pertinentes e importantes poderão estar em diferentes locais e em documentos habitualmente não buscados pelos pesquisadores. Daí, pois, a importância de diversificar e ampliar o âmbito das consultas durante o processo de pesquisar.

$\mathrm{Na}$ comparação com a trajetória portuguesa sobre o início do ensino da enfermagem, de fato, existe paralelismo cronológico, mas quanto à iniciativa, no Brasil, ela foi oficial, por um ato do governo, e lá, uma "iniciativa voluntarista do administrador dos Hospitais da Universidade de Coimbra, a expensas suas e sem reconhecimento oficial".

Como se vê, existe um paralelo histórico entre a criação da primeira escola para enfermeiros no Brasil e em Portugal, quanto à época, exigências para admissão, as repetidas inaugurações, as dificuldades de operacionalização, entre outros fatos, que merecem estudos mais aprofundados, que na realidade estão iniciados. Aqui como lá a iniciativa coube a médicos, mas em Portugal o médico administrador do Hospital recebia o título de enfermeiro-mor, o que poderia induzir a erro, imaginando que se tratava de profissional enfermeiro.

\section{REFERÊNCIAS BIBLIOGRÁFICAS}

(1) Brasil. Decreto n. 791, de 27 de setembro de 1890. Crêa no Hospício Nacional de Alienados uma escola profissional de enfermeiros e enfermeiras. Colecção de Leis Brasileiras (CLB), Rio de Janeiro, v.3, p. 2456, 1890.

(2) Moreira A. Escola de Enfermagem Alfredo Pinto - 100 anos de história. [dissertação]. Rio de Janeiro (RJ): Universidade do Rio de Janeiro; 1990. 2v.

(3) Ludke M, André DA. Pesquisa em educação: abordagem qualitativa. São Paulo: EPU; 1986.

(4) Kirschbaum DIR. Análise histórica das práticas de enfermagem no campo da assistência psiquiátrica no Brasil, no periodo compreendido entre as décadas de 20 e 50. [tese] Campinas (SP): Faculdade de Ciências Médicas da Universidade Estadual de Campinas; 1994.

(5) Moreira MCN. Os profissionais de enfermagem e seus emblemas: identidades e distinções na construção de uma cultura profissional. [dissertação]. Rio de Janeiro (RJ): Escola Nacional de Saúde Pública; 1996.

(6) Itayra MCSP. A mística do silêncio - a enfermagem na Santa Casa de Misericórdia do Rio de Janeiro no século XX. Pelotas: UFPel; 1998.

(7) Brasil. Decreto 142, de 11 de janeiro de 1890. Desanexa o Hospital Nacional de Alienados da Santa Casa de Misericórdia. Colecção de Leis Brasileiras (CLB), Rio de Janeiro, janeiro/março de 1890.

(8) Brasil. Decreto 896, de 29 de junho de 1892. Regulamenta a Assistência Médico-Legal aos Alienados e consolida as disposições, em vigor, relativas aos diferentes serviços. Colecção de Leis Brasileiras (CLB), Rio de Janeiro, v.2, 1892.

(9) Arquivo Nacional. Relatório do Hospício Nacional de Alienados. Rio de Janeiro: 1899.

(10) Arquivo Nacional. Relatório do Hospício Nacional de Alienados. Rio de Janeiro: 1900.

(11) Arquivo Nacional. Relatório do Hospício Nacional de Alienados. Rio de Janeiro: 1901.

(12) Ballariny H. Evolução histórica da assistência médico-social. Rev Paul Hosp 1956; 4(3):20-4.

(13) Soares MI Da blusa de brim à touca branca: contributo para a história do ensino de enfermagem em Portugal, 1880-1950. Lisboa: Educa/ Associação Portuguesa de Enfermeiros; 1997.

(14) Gussi MA. Institucionalização da psiquiatria e do ensino de enfermagem no Brasil. [dissertação]. Ribeirão Preto (SP): Escola de Enfermagem de Ribeirão Preto/USP, 1987.

Artigo recebido em 07/02/02

Artigo aprovado em 21/03/03 